\title{
Cost-Effectiveness of Treatment Sequences of Chemotherapies and Targeted Biologics for Elderly Metastatic Colorectal Cancer Patients
}

\author{
Rohan C. Parikh, MS, PhD; Xianglin L. Du, MB, MS, PhD; \\ Morgan O. Robert, PhD; and David R. Lairson, PhD
}

\begin{abstract}
BACKGROUND: Treatment patterns for metastatic colorectal cancer (mCRC) patients have changed considerably over the last decade with the introduction of new chemotherapies and targeted biologics. These treatments are often administered in various sequences with limited evidence regarding their cost-effectiveness.

OBJECTIVE: To conduct a pharmacoeconomic evaluation of commonly administered treatment sequences among elderly mCRC patients.
\end{abstract}

METHODS: A probabilistic discrete event simulation model assuming Weibull distribution was developed to evaluate the cost-effectiveness of the following common treatment sequences: (a) first-line oxaliplatin/ irinotecan followed by second-line oxaliplatin/irinotecan + bevacizumab (0I-0IB); (b) first-line oxaliplatin/irinotecan + bevacizumab followed by second-line oxaliplatin/irinotecan + bevacizumab (0IB-0IB); (c) OI-OIB followed by a third-line targeted biologic (0I-OIB-TB); and (d) OIB-0IB followed by a third-line targeted biologic (OIB-OIB-TB). Input parameters for the model were primarily obtained from the Surveillance, Epidemiology, and End Results-Medicare linked dataset for incident mCRC patients aged 65 years and older diagnosed from January 2004 through December 2009. A probabilistic sensitivity analysis was performed to account for parameter uncertainty. Costs (2014 U.S. dollars) and effectiveness were discounted at an annual rate of $3 \%$.

RESULTS: In the base case analyses, at the willingness-to-pay (WTP) threshold of $\$ 100,000$ /quality-adjusted life-year (QALY) gained, the treatment sequence OIB-0IB (vs. OI-0IB) was not cost-effective with an incremental cost-effectiveness ratio (ICER) per patient of \$119,007/QALY; OI-OIB-TB (vs. OIB-0IB) was dominated; and OIB-0IB-TB (vs. OIB-0IB) was not cost-effective with an ICER of $\$ 405,857 /$ QALY. Results similar to the base case analysis were obtained assuming log-normal distribution. Costeffectiveness acceptability curves derived from a probabilistic sensitivity analysis showed that at a WTP of $\$ 100,000 /$ QALY gained, sequence OI-OIB was $34 \%$ cost-effective, followed by OIB-OIB $(31 \%)$, OI-OIB-TB $(20 \%)$, and 이B-0IB-TB (15\%).

CONCLUSIONS: Overall, survival increases marginally with the addition of targeted biologics, such as bevacizumab, at first line and third line at substantial costs. Treatment sequences with bevacizumab at first line and targeted biologics at third line may not be cost-effective at the commonly used threshold of $\$ 100,000 /$ Q ALY gained, but a marginal decrease in the cost of bevacizumab may make treatment sequences with first-line bevacizumab cost-effective. Future economic evaluations should validate the study results using parameters from ongoing clinical trials.

J Manag Care Spec Pharm. 2017;23(1):64-73

Copyright $\odot 2017$, Academy of Managed Care Pharmacy. All rights reserved.

\section{What is already known about this subject}

Treatments for metastatic colorectal cancer (mCRC) have changed considerably over the last decade.

The cost to treat and manage mCRC patients are high and may increase considerably as new treatments become part of the treatment sequences.

Several cost-effectiveness studies have been conducted that evaluated first-line or second-line treatments for mCRC patients, but there is no evidence with regards to cost-effectiveness of the most commonly used treatment sequences.

\section{What this study adds}

This study identifies the most commonly used treatment sequences among elderly mCRC patients and conducts a cost-effectiveness evaluation using parameters derived from real-world data. Real-world data render this study's findings more generalizable and informs decision makers regarding the cost-effectiveness of commonly used sequences in day-to-day clinical practice. As more treatments and lines of treatments were administered, survival was prolonged marginally but with considerable increase in costs; addition of first-line and third-line targeted biologics were not cost-effective at the willingness-to-pay threshold of $\$ 100,000 /$ QALY gained.

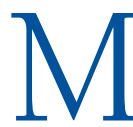
etastatic colorectal cancer (mCRC) has a poor prognosis, with an overall survival rate of 5\%-13\% at 5 years. ${ }^{1,2}$ Treatments for mCRC have changed considerably over the last decade with the approval of oxaliplatin, irinotecan, bevacizumab, cetuximab, and panitumumab. ${ }^{3-7}$ Irinotecan- and oxaliplatin-based chemotherapy regimens are the recommended and most commonly administered first- and second-line regimens, while the addition of bevacizumab has been considered an effective option as first- and second-line treatments. ${ }^{8}$ Administration of cetuximab or panitumumab may also be deemed appropriate for patients with wild type KRAS mutations. ${ }^{4}$ With multiple treatment options available to prolong survival for $\mathrm{mCRC}$ patients, clinicians can provide a treatment continuum by administering treatment sequences with multiple lines of treatment. 


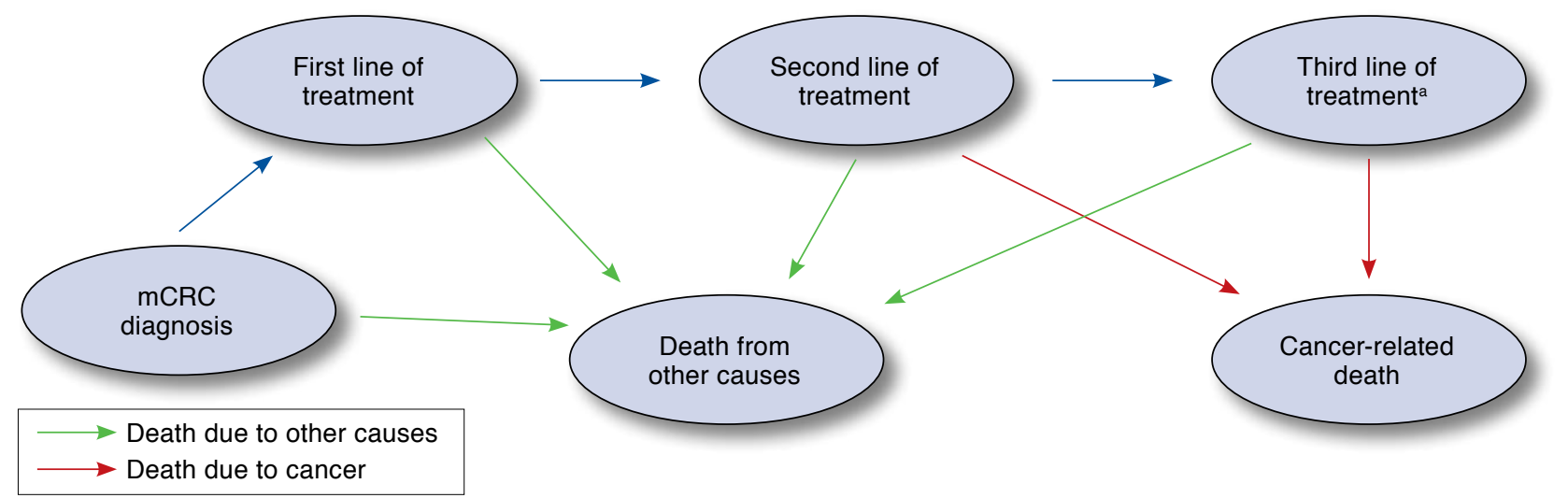

${ }^{a}$ Only for sequences with 3 lines of treatment. $m C R C=$ metastatic colorectal cancer.

Notably, mCRC patients cost twice as much compared with CRC patients ( $\$ 121,800$ vs. $\$ 61,800$ per patient per year) and are likely to receive more regimens, resulting in more increased costs. ${ }^{9-11}$ A study by Song et al. (2010) found that mCRC costs $\$ 14,565$ more per patient per month compared with noncancer patients, and systemic treatment accounted for $17.5 \%$ of this incremental cost. ${ }^{12}$ Moreover, from 2004 to 2008, about a 5\% increase (4.8\%-9.4\%) has been reported in the cost share of targeted biologics. ${ }^{12}$ So, the cost to treat and manage mCRC patients is significant and may increase considerably as new treatments become part of the treatment sequences for mCRC patients. Economic evaluation of treatment sequences with multiple lines of treatment is thus needed to assess how costeffectively health care resources are being used.

Several cost-effectiveness studies have evaluated first-line or second-line treatments for mCRC patients, ${ }^{13-17}$ but only Wong et al. (2009) has assessed cost-effectiveness of treatment sequences for $\mathrm{mCRC}$ patients using parameters primarily from clinical trials and with the majority of patients aged younger than 65 years. ${ }^{18}$ More recently, Woldemichael et al. (2016) assessed the cost-effectiveness of second-line treatments that varied by first-line agents. ${ }^{19}$ In contrast, our study evaluated the cost-effectiveness of treatment sequences using real-world SEER-Medicare data. The objective of the study was to conduct a decision analytic pharmacoeconomic evaluation of treatment sequences for patients with mCRC.

\section{Methods}

\section{Data Source and Study Population}

The Surveillance, Epidemiology, and End Results (SEER)Medicare linked database provided real-world data for this study (a detailed description is provided in Appendix A, available in online article). Patients aged 65 years and older were included who were newly diagnosed from January 2004 to December 2009 with American Joint Cancer Committee stage IV disease (i.e., $\mathrm{mCRC}$ ), defined using the staging variable in SEER registry data. The study was restricted to patients diagnosed after 2004, since drugs such as oxaliplatin, bevacizumab, and cetuximab were approved by the U.S. Food and Drug Administration (FDA) in 2004 for treating mCRC. Patients were excluded if their diagnoses were based on an autopsy/ death certificate (since patients had already died at diagnosis) and also if they died within 30 days of diagnosis because sufficient follow-up to assess treatment sequences would not be available for these patients. ${ }^{5,20,21}$ For completeness of the health care utilization data, patients who were enrolled in Medicare Parts A and B without any health maintenance organization (HMO) enrollment from the time of diagnosis to death or end of study (December 31, 2010) were included. Similar inclusion/exclusion criteria have been used by previous studies that have used the SEER-Medicare data. ${ }^{20,22-25}$ A total of 9,819 mCRC patients met the inclusion/exclusion criteria (Appendix $\mathrm{B}$, available in online article), of which 4,418 received treatment with either chemotherapy or targeted therapy, and 2,534 received second-line therapy.

\section{Treatment Sequences}

Treatment sequences of multiline combinations of systemic chemotherapy and targeted biologics were compared. Therapies approved by the FDA for mCRC patients during the time of this study (2004-2010) and recommended by the National Comprehensive Cancer Network (i.e., 5-florouracil, irinotecan, oxaliplatin, bevacizumab, cetuximab, and panitumumab) were 
considered eligible for first-, second-, and third-line treatments. ${ }^{6,7,26}$ Treatment lines were identified using methodology used by previous studies, ${ }^{27-30}$ and a detailed description of the methodology is provided in Appendix A. Among patients who received at least 2 lines of treatments $(n=2,534)$, first- to thirdline treatments were combined to define treatment sequences. ${ }^{30}$

In our previous work, we identified commonly used treatment sequences for mCRC patients, ${ }^{30}$ which were compared in this economic evaluation. The treatment sequences are as follows: 1. First-line oxaliplatin/irinotecan followed by second-line oxaliplatin/irinotecan + bevacizumab (OI-OIB)

2. First-line oxaliplatin/irinotecan + bevacizumab followed by second-line oxaliplatin/irinotecan + bevacizumab (OIB-OIB)

3. First-line oxaliplatin/irinotecan followed by second-line oxaliplatin/irinotecan + bevacizumab followed by a thirdline targeted biologic (OI-OIB-TB)

4. First-line oxaliplatin/irinotecan + bevacizumab followed by second-line oxaliplatin/irinotecan + bevacizumab followed by a third-line targeted biologic (OIB-OIB-TB)

Treatment sequences OI-OIB, OIB-OIB, OI-OIB-TB, and OIB-OIB-TB were received by $32 \%(n=821)$ of the mCRC patients who received treatment, while the other $68 \%$ ( $n=1,713)$ received sequences with various first-, second-, and third-line combinations. Of the 821 who received commonly administered treatment sequences, OI-OIB was received by $22 \%(\mathrm{n}=178)$, OIB-OIB by $21 \%(\mathrm{n}=169)$, OI-OIB-TB by $33 \%$ $(\mathrm{n}=275)$, and OIB-OIB-TB by $24 \%(\mathrm{n}=199$; Appendix C, available in online article).

\section{Model}

A probabilistic discrete event simulation model, also referred as a time-to-event model, was developed to estimate the costeffectiveness of treatment sequences, assuming a U.S. national payer (Medicare) perspective and using the TreeAge Pro 2015 software (TreeAge Software, Williamston, MA). ${ }^{31,32}$ In comparison with conventional Markov models, where time is divided into fixed cycle lengths, time in a discrete event simulation model is treated as continuous, and time-to-events for each individual are modeled as they occur longitudinally.

At the decision node, the model branched into 4 sequence alternatives: (1) OI-OIB, (2) OIB-OIB, (3) OI-OIB-TB, and (4) OIB-OIB-TB. The model structure is shown in Figure 1. Using microsimulation, individual patients traveled through the treatment pathway (i.e., events in the discrete event simulation model). Patients entered the model after being newly diagnosed with $\mathrm{mCRC}$ and progressed longitudinally to receive first-line and second-line treatments. For sequences OI-OIB and OIBOIB, patients may die because of cancer after second-line treatment, while for sequences OI-OIB-TB and OIB-OIB-TB, patients receive third-line treatment and then progress to cancer-related death. However, at any point in the model horizon of 10 years, patients could die because of causes other than cancer. Treatment-line transitions were modeled using parametric survival distributions, and rewards aggregated were total health care costs and quality-adjusted life-years (QALYs). Costs and effectiveness were discounted at an annual rate of 3\%. ${ }^{33}$

\section{Parametric Survival Distributions}

Treatment-line transition time and time to death (Figure 1) were individually estimated for each treatment sequence by conducting an inverse probability treatment weighted parametric survival analysis using the SEER-Medicare data (Appendix A). ${ }^{34}$ Parametric survival regressions were modeled using Weibull distribution, since it is the most commonly used distribution for predicting cancer progression and survival. ${ }^{35-37}$ Regressions computed for each treatment sequence were as follows: (a) diagnosis to first-line treatment (all sequences), (b) first-line to second-line treatment (all sequences), (c) secondline treatment to cancer-related death (sequences OI-OIB and OIB-OIB), (d) second-line treatment to end of secondline treatment (sequences OI-OIB-TB and OIB-OIB-TB), and (e) third-line treatment to cancer-related death (sequences OI-OIB-TB and OIB-OIB-TB). From each regression, Weibull shape and scale parameters were estimated, which in turn were used to determine the time for each transition in the discrete event simulation model. Death because of causes other than cancer was modeled using U.S. vital statistics for an individual aged 75-80 years (mean age of mCRC diagnosis), assuming an exponential distribution. ${ }^{38,39}$

\section{Costs}

The Medicare amount paid was used to estimate the total health care costs. Total health care costs were estimated from diagnosis until death or end of the study (December 31, 2010) using claims for inpatient, outpatient, physician, skilled nursing facility, hospice, and durable medical equipment, since cancer treatment may affect overall morbidity. As cost data were aggregated from 2004 to 2010 and were from different U.S. geographic locations, county-level price adjusters developed by Brown et al. (2002) were used to adjust for geographical location and inflation. ${ }^{40}$ Price adjusters allowed the conversion of costs to 2009 U.S. dollars, and further adjustment to 2014 U.S. dollars was conducted using the medical care component of the Consumer Price Index. ${ }^{41}$ Total health care costs for each treatment sequence were divided into average monthly costs for each line of treatment. For example, for treatment sequence OI-OIB, total health care costs per month were estimated from diagnosis to first-line treatment, first-line to second-line treatment, and second-line treatment to death. Similar estimations were conducted for sequences OIB-OIB, OI-OIB-TB, and OIB-OIB-TB. 


\section{Health State Utilities}

Health state utility for a newly diagnosed mCRC patient was obtained from the study by Ramsey et al. (2000), ${ }^{42}$ while utilities specific to treatment line were obtained from the recent study by Stein et al. (2014). ${ }^{43}$ The mean ( \pm standard deviation) utility was assumed to be $0.841( \pm 0.120)$ at diagnosis, 0.741 $( \pm 0.230)$ at first-/second-line treatments and $0.731( \pm 0.292)$ at third-line treatment. Similar health state utilities have been estimated by other studies conducted for mCRC patients. ${ }^{4-46}$

\section{Cost-Effectiveness Analysis}

Cost-effectiveness of treatment sequences was assessed by conducting microsimulation discrete event simulation analyses for 100,000 mCRC patients in each treatment sequence. Costeffectiveness was evaluated as incremental cost-effectiveness ratio (ICER) and net monetary benefit (NMB). ICER is a ratio of incremental total health care costs and incremental effectiveness and was presented as ICER per QALY gained. NMB is a rearrangement of ICER and can be represented as $\mathrm{NMB}=$ (willingness to pay [WTP] $\times$ incremental effectiveness) - incremental total health care costs. Cost-effectiveness for treatment sequences was evaluated at the commonly used ICER threshold of $\$ 100,000 /$ QALY gained in the United States or if NMB was greater than zero. ${ }^{33,47}$

\section{Sensitivity Analyses and Validation}

A series of sensitivity analyses were conducted. First, although Weibull is a commonly used distribution for cancer survival, the analyses showed log-normal to best fit (lowest Akaike Information Criteria value) survival for all treatment sequences. All base case analyses were therefore repeated using log-normal distribution. Second, a 1-way sensitivity analysis was conducted by varying the background mortality for patients aged 65-74 years (annual probability: 0.012) to 85 years and older (annual probability: 0.115) using U.S. vital statistics. ${ }^{38}$ Third, base case cost-effectiveness analysis was conducted without adjusting for health state utilities (i.e., quality of life), since instruments used to estimated health state utilities may lack sensitivity, and patients may value health states more than nonpatients. ${ }^{48}$ Fourth, stochastic probabilistic sensitivity analysis was conducted for 10,000 iterations with 100,000 patients sampled in each iteration (i.e., 1 billion patients). The output from the probabilistic sensitivity analysis was presented as cost-effectiveness acceptability curves (CEACs), which graphically demonstrated the percentage of cost-effective iterations for each treatment sequence at the given WTP threshold such that, at each WTP, the proportions of iterations being costeffective summed to $100 \% .35,49$ Additional CEACs comparing treatment sequences OIB-OIB, OI-OIB-TB, and OIB-OIB-TB to OI-OIB were computed.

\section{Assumptions}

Two main assumptions were made for the model. First, for sequences OI-OIB-TB and OIB-OIB-TB, after the end of second-line treatment, patients were assumed to go directly to the start of third-line treatment without a treatment gap. This assumption was made to exclude the time between the end of second-line treatment and the start of third-line treatment, thereby allowing adequate comparison between sequences with 3 lines of treatment (OI-OIB-TB and OIB-OIB-TB) and sequences with 2 lines of treatment (OI-OIB and OIB-OIB). Although about $50 \%$ of patients in the data were found to have immediately switched to the third line of treatment after the end of the second line, an additional analysis allowing for the treatment gap between the end of second-line treatment and the start of third-line treatment was conducted.

Second, cancer-related death in the time-to-event parametric survival analysis was characterized if the cause of death was reported either as any type of cancer or unknown. A similar criterion has been used in a previous study to define cancerrelated death, ${ }^{20}$ and sampling uncertainty for cancer-related death was taken into account because of the probabilistic nature of the discrete event simulation model.

\section{Results}

Characteristics of patients receiving the treatment sequences OI-OIB, OIB-OIB, OI-OIB-TB, and OIB-OIB-TB are shown in Table 1. Differences among treatment sequence groups were only observed for comorbidity score, other metastasis site, and year of diagnosis. Although not statistically significant, sequences with bevacizumab in first-line treatment were received more frequently by patients with metastatic colon cancer as compared with patients with metastatic rectal cancer (i.e., OIB-OIB and OIB-OIB-TB; Table 1). Overall, the treatment sequence groups were comparable for observed baseline factors. Input parameters for Weibull distribution (shape and scale) and average monthly costs by sequences are shown in Appendices D and E (available in online article), respectively. The average monthly cost from diagnosis to first-line treatment ranged from $\$ 13,215$ (OIB-OIB) to $\$ 14,585$ (OI-OIB). As expected, first-line to second-line monthly costs were observed to be relatively higher for sequences with bevacizumab in first-line treatment. Average monthly costs for second-line treatment to death, second-line treatment to end of secondline treatment, and third-line treatment to death for treatment sequences ranged from $\$ 12,004$ to $\$ 15,438$.

Table 2 shows the discrete event simulation model estimated total health care costs, total QALYs, ICER per QALY, and NMB for each mCRC patient using the Weibull distribution. The total health care costs were lowest for OI-OIB $(\$ 305,868)$ and highest for OIB-OIB-TB $(\$ 402,228)$. Similarly, the lowest QALYs 
Cost-Effectiveness of Treatment Sequences of Chemotherapies and

Targeted Biologics for Elderly Metastatic Colorectal Cancer Patients

TABLE 1 Characteristics of Metastatic Colorectal Cancer Patients by Treatment Sequences

\begin{tabular}{|c|c|c|c|c|c|c|c|c|c|}
\hline \multirow[b]{2}{*}{ Characteristics } & \multicolumn{2}{|c|}{ OI-OIB } & \multicolumn{2}{|c|}{ OIB-OIB } & \multicolumn{2}{|c|}{ OI-OIB-TB } & \multicolumn{2}{|c|}{ OIB-OIB-TB } & \multirow[b]{2}{*}{$P$ Value } \\
\hline & \multicolumn{2}{|c|}{$\mathrm{n}=178$} & \multicolumn{2}{|c|}{$\mathrm{n}=169$} & \multicolumn{2}{|c|}{$\mathrm{n}=275$} & \multicolumn{2}{|c|}{$\mathrm{n}=199$} & \\
\hline $65-69$ & 56 & $(31.5)$ & 56 & $(33.1)$ & 108 & $(39.3)$ & 81 & $(40.7)$ & \\
\hline $70-74$ & 57 & $(32.0)$ & 49 & $(29.0)$ & 84 & $(30.6)$ & 72 & $(36.2)$ & \\
\hline $75-79$ & 47 & $(26.4)$ & 38 & $(22.5)$ & 56 & $(20.4)$ & 32 & $(16.1)$ & \\
\hline $80+$ & 18 & $(10.1)$ & 26 & $(15.4)$ & 27 & $(9.8)$ & 14 & $(7.0)$ & \\
\hline Race/ethnicity, n (\%) & & & & & & & & & 0.4093 \\
\hline Caucasians & 144 & $(80.9)$ & 142 & $(84.0)$ & 235 & $(85.5)$ & 173 & $(86.9)$ & \\
\hline Others & 34 & $(19.1)$ & 27 & $(16.0)$ & 40 & $(14.6)$ & 26 & $(13.1)$ & \\
\hline Gender, n (\%) & & & & & & & & & 0.1751 \\
\hline Male & 86 & $(48.3)$ & 91 & (53.9) & 161 & $(58.6)$ & 113 & $(56.8)$ & \\
\hline Female & 92 & $(51.7)$ & 78 & $(46.2)$ & 114 & $(41.5)$ & 86 & $(43.2)$ & \\
\hline Marital status, n (\%) & & & & & & & & & 0.2983 \\
\hline Married & 114 & $(64.0)$ & 102 & $(60.4)$ & 189 & $(68.7)$ & 125 & $(62.8)$ & \\
\hline Unmarried/unknown & 64 & $(36.0)$ & 67 & $(39.6)$ & 86 & $(31.3)$ & 74 & $(37.2)$ & \\
\hline Tumor grade, $\mathbf{n}(\%)$ & & & & & & & & & 0.7064 \\
\hline Well/moderately differentiated & 105 & $(59.0)$ & 107 & $(63.3)$ & 176 & $(64.0)$ & 121 & $(60.8)$ & \\
\hline Poorly/undifferentiated/unknown & 73 & $(41.0)$ & 62 & $(36.7)$ & 99 & $(36.0)$ & 78 & $(39.2)$ & \\
\hline Comorbidity scores, n (\%) & & & & & & & & & $0.0129^{a}$ \\
\hline 0 & 84 & $(47.2)$ & 97 & $(57.4)$ & 173 & $(62.9)$ & 123 & $(61.8)$ & \\
\hline 1 & 69 & $(38.8)$ & 44 & $(26.0)$ & 71 & $(25.8)$ & 49 & $(24.6)$ & \\
\hline$\geq 2$ & 25 & $(14.0)$ & 28 & $(16.6)$ & 31 & $(11.3)$ & 27 & $(13.6)$ & \\
\hline \multicolumn{10}{|l|}{ Metastasis, n (\%) } \\
\hline Liver & 126 & $(70.8)$ & 128 & $(75.7)$ & 206 & $(74.9)$ & 143 & $(71.9)$ & 0.6458 \\
\hline Lung & 22 & $(12.4)$ & 26 & $(15.4)$ & 41 & $(14.9)$ & 31 & $(15.6)$ & 0.8079 \\
\hline Abdomen & 31 & $(17.4)$ & 25 & $(14.8)$ & 57 & $(20.7)$ & 37 & $(18.6)$ & 0.4608 \\
\hline Other & 34 & $(19.1)$ & 18 & $(10.7)$ & 43 & $(15.6)$ & 19 & $(9.6)$ & $0.0248^{\mathrm{a}}$ \\
\hline Unknown & 31 & $(17.4)$ & 24 & $(14.2)$ & 37 & $(13.5)$ & 29 & $(14.6)$ & 0.7010 \\
\hline Cancer site, n (\%) & & & & & & & & & 0.0829 \\
\hline Colon & 128 & $(71.9)$ & 135 & $(79.9)$ & 194 & $(70.6)$ & 155 & $(77.9)$ & \\
\hline Rectal & 50 & $(28.1)$ & 34 & $(20.1)$ & 81 & $(29.5)$ & 44 & $(22.1)$ & \\
\hline SES (poverty), n (\%) & & & & & & & & & 0.2732 \\
\hline First (low SES) & 34 & $(19.1)$ & 41 & $(24.3)$ & 62 & $(22.6)$ & 41 & $(20.6)$ & \\
\hline Second & 48 & $(27.0)$ & 37 & $(21.9)$ & 56 & $(20.4)$ & 53 & $(26.6)$ & \\
\hline Third & 43 & $(24.2)$ & 54 & $(32.0)$ & 69 & $(25.1)$ & 53 & $(26.6)$ & \\
\hline Fourth (high SES) & 53 & $(29.8)$ & 37 & $(21.9)$ & 88 & $(32.0)$ & 52 & $(26.1)$ & \\
\hline Region, n (\%) & & & & & & & & & 0.0915 \\
\hline Midwest & 20 & $(11.2)$ & 15 & $(8.9)$ & 31 & $(11.3)$ & 18 & $(9.1)$ & \\
\hline Northeast & 38 & $(21.4)$ & 36 & $(21.3)$ & 55 & $(20.0)$ & 41 & $(20.6)$ & \\
\hline South & 49 & $(27.5)$ & 48 & $(28.4)$ & 45 & $(16.4)$ & 45 & $(22.6)$ & \\
\hline West & 71 & $(39.9)$ & 70 & $(41.4)$ & 144 & $(52.4)$ & 95 & $(47.7)$ & \\
\hline Urban/rural, n (\%) & & & & & & & & & 0.1894 \\
\hline Less urban/rural & 19 & $(10.7)$ & 24 & $(14.2)$ & 22 & $(8.0)$ & 18 & $(9.1)$ & \\
\hline Metro/urban & 159 & $(89.3)$ & 145 & $(85.8)$ & 253 & $(92.0)$ & 181 & $(91.0)$ & \\
\hline Year of diagnosis, n (\%) & & & & & & & & & $<0.0001^{\mathrm{a}}$ \\
\hline $2004-2005$ & 56 & $(31.5)$ & 40 & $(23.7)$ & 109 & $(39.6)$ & 52 & $(26.1)$ & \\
\hline $2006-2007$ & 48 & $(27.0)$ & 56 & $(33.1)$ & 90 & $(32.7)$ & 95 & $(47.7)$ & \\
\hline $2008-2009$ & 74 & (41.6) & 73 & $(43.2)$ & 76 & (27.6) & 52 & $(26.1)$ & \\
\hline
\end{tabular}

a Significant at $\alpha=0.05$.

OI-OIB = first-line oxaliplatin/irinotecan followed by second-line oxaliplatin/irinotecan + bevacizumab; OIB-OIB =first-line oxaliplatin/irinotecan + bevacizumab followed by second-line oxaliplatin/irinotecan + bevacizumab; OI-OIB-TB = OI-OIB followed by a third-line targeted biologic; OIB-OIB-TB=OIB-OIB followed by a third-line targeted biologic; SES = socioeconomic status. 
Cost-Effectiveness of Treatment Sequences of Chemotherapies and

Targeted Biologics for Elderly Metastatic Colorectal Cancer Patients

\begin{tabular}{|c|c|c|c|c|c|c|}
\hline $\begin{array}{l}\text { Treatment } \\
\text { Sequences }\end{array}$ & $\begin{array}{l}\text { Total Health } \\
\text { Care Cost, \$ }\end{array}$ & $\begin{array}{c}\text { Incremental Health } \\
\text { Care Cost, } \$\end{array}$ & Total QALY & Incremental QALY & ICER per QALY, \$ & $\mathrm{NMB},{ }^{\mathrm{b}} \$$ \\
\hline \multicolumn{7}{|c|}{ Weibull distribution } \\
\hline OI-OIB & 305,868 & - & 1.42 & - & - & \\
\hline OIB-OIB & 333,981 & 28,113 & 1.65 & 0.23 & 119,636 & $-5,113$ \\
\hline OI-OIB-TB & 355,690 & 21,709 & 1.65 & Dominated & Dominated & Dominated \\
\hline OIB-OIB-TB & 402,228 & 68,247 & 1.82 & 0.17 & 405,857 & $-51,247$ \\
\hline \multicolumn{7}{|c|}{ Log-normal distribution } \\
\hline OI-OIB & 308,548 & - & 1.43 & - & & \\
\hline OIB-OIB & 336,875 & 28,327 & 1.67 & 0.24 & 119,007 & $-4,327$ \\
\hline OI-OIB-TB & 361,025 & 24,150 & 1.68 & 0.01 & Extended dominance & Extended dominance \\
\hline OIB-OIB-TB & 415,102 & 78,227 & 1.88 & 0.21 & 370,444 & $-57,227$ \\
\hline \multicolumn{7}{|c|}{$\begin{array}{l}\text { aArranged in the order of increasing costs. } \\
\text { bAt willingness to pay of } \$ 100,000 \text {. } \\
\text { ICER=incremental cost-effectiveness ratio; NMB = net monetary benefit; OI-OIB =first-line oxaliplatin/irinotecan followed by second-line oxaliplatin/irinotecan + bevaci- } \\
\text { zumab; OIB-OIB=first-line oxaliplatin/irinotecan + bevacizumab followed by second-line oxaliplatin/irinotecan + bevacizumab; OI-OIB-TB=OI-OIB followed by a third- } \\
\text { line targeted biologic; OIB-OIB-TB =OIB-OIB followed by a third-line targeted biologic; QALY=quality-adjusted life-years. }\end{array}$} \\
\hline
\end{tabular}

were estimated for OI-OIB, followed by OI-OIB-TB, OIB-OIB, and OIB-OIB-TB. In the base case analysis assuming a Weibull distribution, the ICER for OIB-OIB as compared with OI-OIB was $\$ 119,636 / \mathrm{QALY}$ gained. OI-OIB-TB was dominated (i.e., more costly and less effective) by OIB-OIB, while the ICER for OIB-OIB-TB as compared with OIB-OIB was $\$ 405,857 /$ QALY gained. Similar ICER results were obtained for OIB-OIB versus OI-OIB (\$119,007/QALY gained) and OIB-OIB-TB versus OIBOIB (\$370,444/QALY gained) in the sensitivity analysis using a log-normal distribution. The NMB was less than zero for OIBOIB versus OI-OIB (Weibull: $-\$ 5,113$; log-normal: $-\$ 4,327$ ), as well as for OIB-OIB-TB versus OIB-OIB (Weibull: - $\$ 51,247$; log-normal: $-\$ 57,227$ ).

Scenario analysis allowing for a treatment gap between the end of second-line treatment and the start of third-line treatment showed results similar to the base case analysis for OIB-OIB versus OI-OIB with ICER/QALY gained of $\$ 118,984$ (Table 3). OI-OIB-TB showed extended dominance, so ICER/ QALY gained for OIB-OIB-TB as compared with OIB-OIB was $\$ 290,068$ (Table 3). One-way sensitivity analysis varying background mortality from 0.012 to 0.115 (annual probabilities) showed results similar to that of the base case analysis. ICER for OIB-OIB as compared with OI-OIB ranged from $\$ 102,741$ to $\$ 120,452 /$ QALY gained, while for OIB-OIB-TB as compared with OIB-OIB, ICER/QALY gained ranged from $\$ 379,144$ to $\$ 413,569$. In a sensitivity analysis without adjusting for health state utilities, OIB-OIB was found to be cost-effective at $\$ 84,673 /$ life-year gained, and OI-OIB-TB showed extended dominance, while OIB-OIB-TB was not cost-effective with an ICER of $\$ 276,955 /$ life-year gained.
Probabilistic sensitivity analyses results, presented as CEACs, are shown in Figure 2, with WTP varied from $\$ 0$ to $\$ 1,000,000$. In the base case model (Weibull distribution), at the WTP threshold of $\$ 100,000 /$ QALY gained, sequence OI-OIB was 34\% cost-effective, followed by OIB-OIB (31\%), OI-OIB-TB (20\%), and OIB-OIB-TB (15\%). Between the WTP of $\$ 150,000 / \mathrm{QALY}$ and $\$ 450,000 / \mathrm{QALY}$, OIB-OIB was the most cost-effective sequence. However, if the WTP increased more than $\$ 450,000 / \mathrm{QALY}$, OIB-OIB-TB became the most cost-effective sequence. Similar CEAC results were found using a log-normal distribution, except that OIB-OIB-TB became the most cost-effective treatment sequence starting at the WTP threshold of $\$ 380,000 /$ QALY. As compared with common reference OI-OIB at WTP of $\$ 100,000 /$ QALY, OIB-OIB, OI-OIB-TB, and OIB-OIB-TB were $47 \%, 41 \%$, and $36 \%$ costeffective, respectively.

\section{Discussion}

A cost-effectiveness evaluation was conducted of treatment sequences OI-OIB, OIB-OIB, OI-OIB-TB, and OI-OIB-TB, which were the most commonly received sequences by elderly mCRC patients. Overall, as more treatments/lines were administered, survival was prolonged marginally but with considerable increase in costs. Addition of bevacizumab at first line may not be cost-effective at the WTP threshold of $\$ 100,000 /$ QALY gained. Similarly, addition of a third-line targeted biologic (OIB-OIB-TB) was also not cost-effective. Notably, the sequence with a third-line targeted biologic without bevacizumab at first-line treatment (OI-OIB-TB) was dominated by the 2-line sequence (OIB-OIB). 
TABLE 3 Incremental Cost-Effectiveness Ratios and Net Monetary Benefit with Time Between Second-Line and Third-Line Treatments Using Weibull Distribution

\begin{tabular}{|c|c|c|c|c|c|c|}
\hline $\begin{array}{l}\text { Treatment } \\
\text { Sequences }^{a}\end{array}$ & $\begin{array}{c}\text { Total Health Care } \\
\text { Cost, } \$\end{array}$ & $\begin{array}{c}\text { Incremental Health } \\
\text { Care Cost, } \$\end{array}$ & Total QALY & Incremental QALY & ICER per QALY, \$ & NMB,b \$ \\
\hline OI-OIB & 306,678 & - & 1.42 & - & - & - \\
\hline OIB-OIB & 334,494 & 27,816 & 1.65 & 0.23 & 118,984 & $-4,816$ \\
\hline OI-OIB-TB & 365,472 & 30,978 & 1.75 & 0.09 & Extended dominance & Extended dominance \\
\hline OIB-OIB-TB & 413,032 & 78,538 & 1.92 & 0.27 & 290,068 & $-51,538$ \\
\hline
\end{tabular}

a Arranged in the order of increasing costs.

bAt willingness to pay of $\$ 100,000$.

ICER = incremental cost-effectiveness ratio; $N M B=$ net monetary benefit; OI-OIB = first-line oxaliplatin/irinotecan followed by second-line oxaliplatin/irinotecan +


third-line targeted biologic; OIB-OIB-TB =OIB-OIB followed by a third-line targeted biologic; QALY=quality-adjusted life-years.

Wong et al. found an ICER per QALY gained of $\$ 102,347$ (2008 U.S. dollars) for a 2-line therapy sequence versus a single-line of therapy and an ICER per QALY gained of $\$ 170,896$ (2008 U.S. dollars) for a sequence with bevacizumab in firstline treatment and a targeted biologic in third-line treatment, as compared with a 2-line therapy sequence. ${ }^{18}$ Similar to this study, Wong et al. also found sequences with 3 lines and bevacizumab in first-line treatment to not be cost-effective at WTP of $\$ 100,000 /$ QALY. Moreover, Wong et al. did not adjust for quality of life; sequences were not selected based on real-world treatment patterns; and the model inputs were primarily based on clinical trials with a relatively younger population (aged less than 65 years). To our knowledge, this is the first study to conduct a probabilistic discrete event simulation cost-effectiveness evaluation of commonly administered treatment sequences among elderly mCRC patients using parameters derived from real-world data. Use of real-world data renders the findings more generalizable and informs decision makers about the cost-effectiveness of commonly used sequences in day-to-day clinical practice.

A WTP threshold of $\$ 100,000 /$ QALY gained has been commonly used in the United States, but an update on the value of dialysis, which has been considered an acceptable ICER benchmark, was found to be about \$130,000/QALY gained. ${ }^{47,50}$ Other studies have also considered WTP thresholds of up to $\$ 200,000 / \mathrm{QALY}$ gained to evaluate cost-effectiveness. ${ }^{51,52}$ Assuming a WTP of $\$ 200,000 /$ QALY gained, sequence OIBOIB may be considered cost-effective, but the 3-line sequence (OIB-OIB-TB) remains not cost-effective (Table 2). Threshold analyses conducted to estimate the cost at which OIB-OIB (vs. OI-OIB) and OIB-OIB-TB (vs. OIB-OIB) may become cost-effective at WTP of $\$ 100,000 /$ QALY found OIB-OIB to be cost-effective if the first-line cost would be reduced by $\$ 286$ per month. This is equivalent to about an $11 \%$ decrease in the per-cycle cost of bevacizumab,,$^{53}$ which may be plausible after the patent for bevacizumab expires in the United States in 2019,,$^{51,54}$ and biosimilars for bevacizumab become available.
However, for OIB-OIB-TB to become cost-effective, the cost of the third-line treatment would have to be reduced by the substantial amount of $\$ 4,040$ per month.

Cancer cases in the United States from 2010 to 2030 are projected to increase from 1.6 million to 2.3 million, and the majority of cases (70\%) will occur in older adults. ${ }^{55}$ Cost of cancer care is expected to reach $\$ 157.8$ billion by the year 2020 , under constant incidence and survival rates, primarily because of the aging U.S. population. ${ }^{56} \mathrm{~A}$ nominal $2 \%$ increase in medical costs for the initial phase and last year of life would result in a total cancer cost of $\$ 173$ billion by $2020 .{ }^{56}$ Rising health care costs driven by new medical technology, expanded insurance coverage, and an aging population require the U.S. private and public decision makers to develop and apply costeffective prevention and treatment strategies for cancer.

\section{Limitations}

This study has several limitations that should be considered when interpreting the results. First, parameters derived from observational data were used, which exposes the study to potential selection bias. Although statistical significant differences were only observed on comorbidity score, other metastatic site, and year of diagnosis (Table 1), the inverse probability treatment weighting technique was applied to attenuate this potential bias in parameter estimation. The effect of selection bias because of unmeasured factors remains unknown, and future studies using clinical trial data should be conducted to validate the results.

Second, the primary aim of this study was to compare treatment sequences of chemotherapies or targeted therapies. Surgery, which is an option for healthy elderly mCRC patients along with adjuvant chemotherapy or targeted therapy, was not included ${ }^{57}$ Moreover, with newer therapies being approved for mCRC patients, chemotherapy may be considered the preferred first-line treatment, and a protective effect has been observed for patients receiving chemotherapy versus surgery as initial treatment. ${ }^{58,59}$ Third, this analysis only included 4 of 
A. Cost-Effectiveness Acceptability Curve with Weibull Distribution

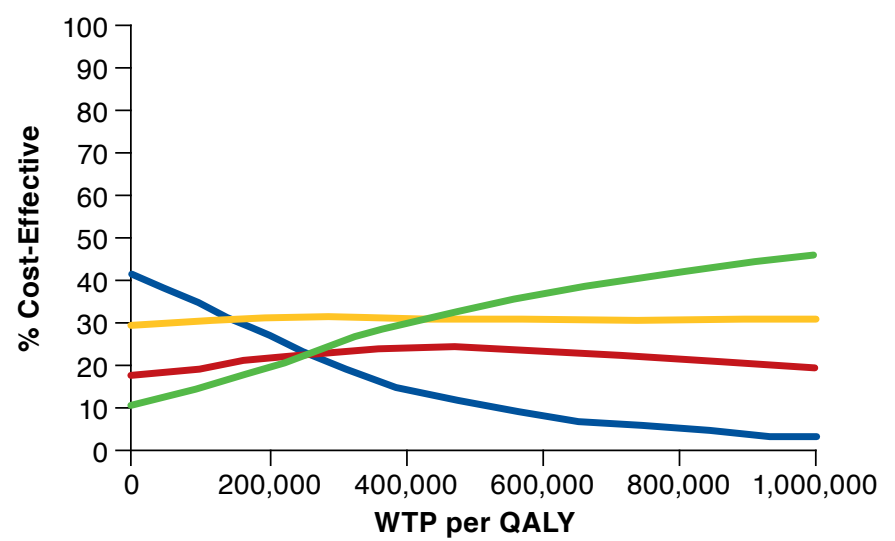

B. Cost-Effectiveness Acceptability Curve with Log-Normal Distribution

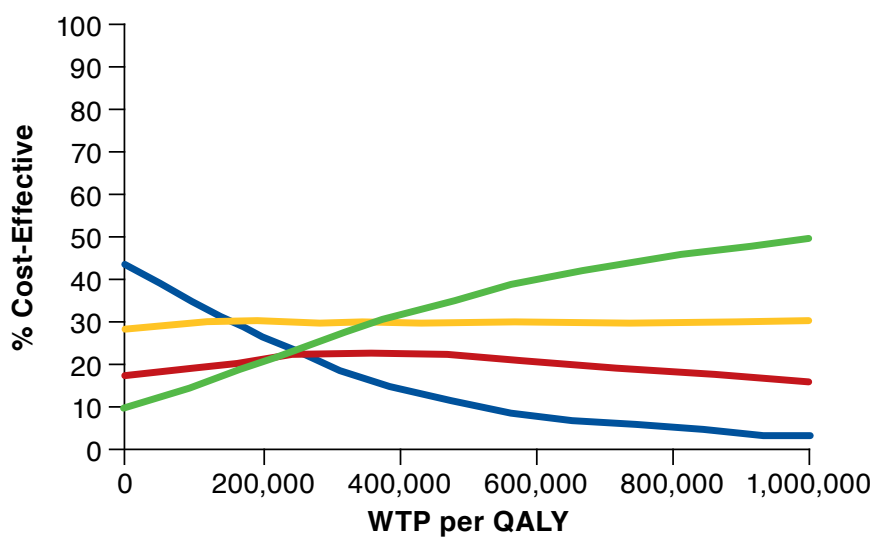

$\longrightarrow$ OI-OIB OI-OIB-TB OIB-OIB $=$ OIB-OIB-TB

OI-OIB = first-line oxaliplatin/irinotecan followed by second-line oxaliplatin/irinotecan + bevacizumab $=$ OIB-OIB =first-line oxaliplatin/irinotecan + bevacizumab followed by second-line oxaliplatin/irinotecan + bevacizumab; OI-OIB-TB=OI-OIB followed by a third-line targeted biologic; OIB-OIB-TB=OIB-OIB followed by a third-line targeted biologic; $Q A L Y=$ quality-adjusted life-year; $W T P=$ willingness to pay.

the most commonly administered sequences (accounting for about 32.4\%); however, these sequences have been identified as commonly administered sequences by other studies, ${ }^{27-29}$ and ongoing clinical trials on sequences are evaluating the efficacy of these sequences. ${ }^{60-62}$

Fourth, findings of this study may only be generalizable to mCRC patients aged 65 years and older and patients who are enrolled in Medicare Parts A and B without enrollment in an HMO. However, the mean age at diagnosis for mCRC patients is 75 years, and Medicare is the primary payer for individuals aged 65 years and older in the United States, ${ }^{39}$ suggesting that the findings are relevant for a majority of the MCRC population.

Finally, the total health care cost did not include retail pharmacy costs, since Medicare Part D data were not available; hence, total health care cost may be underestimated. Nevertheless, the monthly retail pharmacy costs estimated by Song et al. for mCRC patients was marginal (\$348) and may not affect the overall study results. ${ }^{12}$

\section{Conclusions}

For elderly mCRC patients, survival increases marginally with the addition of targeted biologics, such as bevacizumab, at firstline treatment and third-line treatment at substantial costs. Sequences OIB-OIB (vs. OI-OIB) and OIB-OIB-TB (vs. OIBOIB) were not cost-effective at the WTP of $\$ 100,000 /$ QALY gained, while using parameters derived from real-world data. Ongoing clinical trials may provide additional efficacy/toxicity information, and future economic evaluations should validate the study results using parameters from ongoing clinical trials, as well as adopting a broader societal perspective. ${ }^{60-62}$ Thus, treatment sequences with bevacizumab at first-line treatment and targeted biologics at third-line treatment may not be costeffective at the commonly used threshold of $\$ 100,000 /$ QALY gained, but a marginal decrease in the cost of bevacizumab may make treatment sequences with first-line bevacizumab cost-effective.

\section{Authors}

ROHAN C. PARIKH, MS, PhD, RTI Health Solutions, Research Triangle Park, North Carolina, and Division of Management, Policy, and Community Health, School of Public Health, University of Texas Health Science Center at Houston. XIANGLIN L. DU, MB, MS, $\mathrm{PhD}$, Division of Management, Policy, and Community Health and Division of Epidemiology, Human Genetics, and Environmental Sciences, School of Public Health, University of Texas Health Science Center at Houston. MORGAN O. ROBERT, PhD, and DAVID R. LAIRSON, PhD, Division of Management, Policy, and Community Health, School of Public Health, University of Texas Health Science Center at Houston.

AUTHOR CORRESPONDENCE: Rohan C. Parikh, MS, PhD, RTI Health Solutions, 300 Park Offices Dr., Research Triangle Park, NC 27709. Tel.: 919.541.6513; Fax: 919.541.7222; E-mail: rparikh@rti.org. 


\section{DISCLOSURES}

This study was supported in part by a grant from the Agency for Healthcare Research and Quality (R01-HS018956) and in part by a grant from the Cancer Prevention and Research Institute of Texas (RP130051), which were obtained by $\mathrm{Du}$. The authors report no conflicts of interest.

Study concept and design were primarily contributed by Parikh, along with the other authors. All authors participated in data collection, and Parikh took the lead in data interpretation and analysis, along with Lairson and Morgan, with assistance from $\mathrm{Du}$. The manuscript was written primarily by Parikh, along with Lairson, Morgan, and Du, and revised by Parikh.

\section{REFERENCES}

1. Chu E. An update on the current and emerging targeted agents in metastatic colorectal cancer. Clin Colorectal Cancer. 2012;11(1):1-13.

2. National Cancer Institute. Surveillance Epidemiology, and End Results Program. SEER stat fact sheets: colon and rectum cancer. 2015. Available at: http://seer.cancer.gov/statfacts/html/colorect.html. Accessed November 20, 2016

3. Cartwright TH. Treatment decisions after diagnosis of metastatic colorectal cancer. Clin Colorectal Cancer. 2012;11(3):155-66.

4. Lee JJ, Chu E. Sequencing of antiangiogenic agents in the treatment of metastatic colorectal cancer. Clin Colorectal Cancer. 2014;13(3):135-44.

5. Sanoff HK, Goldberg RM. How we treat metastatic colon cancer in older adults. J Geriatr Oncol. 2013;4(4):295-301.

6. National Comprehensive Cancer Network. NCCN clinical practice guidelines in oncology: colon cancer. 2014. Available at: https://www.nccn.org/ professionals/physician_gls/f_guidelines.asp. Accessed November 20, 2016.

7. National Comprehensive Cancer Network. NCCN clinical practice guidelines in oncology: rectal cancer. 2014. Available at: https://www.nccn.org/ professionals/physician_gls/f_guidelines.asp. Accessed November 20, 2016.

8. Bekaii-Saab T, Wu C. Seeing the forest through the trees: a systematic review of the safety and efficacy of combination chemotherapies used in the treatment of metastatic colorectal cancer. Crit Rev Oncol Hematol. 2014:91(1):9-34.

9. Chastek B, Kulakodlu M, Valluri S, Seal B. Impact of metastatic colorectal cancer stage and number of treatment courses on patient healthcare costs and utilization. Postgrad Med. 2013;125(2):73-82.

10. Seal BS, Sullivan SD, Ramsey S, et al. Medical costs associated with use of systemic therapy in adults with colorectal cancer. J Manag Care Pharm. 2013;19(6):461-67. Available at: http://www.jmcp.org/doi/10.18553/ jmcp.2013.19.6.461.

11. Ferro SA, Myer BS, Wolff DA, et al. Variation in the cost of medications for the treatment of colorectal cancer. Am J Manag Care. 2008;14(11):717-25.

12. Song X, Zhao Z, Barber B, Gregory C, Cao Z, Gao S. Cost of illness in patients with metastatic colorectal cancer. J Med Econ. 2010;14(1):1-9.

13. Lange A, Prenzler A, Frank M, Kirstein M, Vogel A, von der Schulenburg J A systematic review of cost-effectiveness of monoclonal antibodies for metastatic colorectal cancer. Eur J Cancer. 2014;50(1):40-49.

14. Tappenden P, Jones R, Paisley S, Carroll C. The cost-effectiveness of bevacizumab in the first-line treatment of metastatic colorectal cancer in England and Wales. Eur J Cancer. 2007;43(17):2487-94.

15. Vijayaraghavan A, Efrusy MB, Göke B, Kirchner T, Santas CC, Goldberg RM. Cost-effectiveness of KRAS testing in metastatic colorectal cancer patients in the United States and Germany. Int J Cancer. 2012;131(2):438-45.

16. Shiroiwa T, Fukuda T, Tsutani K. Cost-effectiveness analysis of bevacizumab combined with chemotherapy for the treatment of metastatic colorectal cancer in Japan. Clin Ther. 2007;29(10):2256-67.

17. Behl AS, Goddard KA, Flottemesch TJ, et al. Cost-effectiveness analysis of screening for KRAS and BRAF mutations in metastatic colorectal cancer. J Natl Cancer Inst. 2012;104(23):1785-95.
18. Wong Y, Meropol NJ, Speier W, Sargent D, Goldberg RM, Beck JR. Cost implications of new treatments for advanced colorectal cancer. Cancer. 2009;115(10):2081-91.

19. Woldemichael A, Onukwugha E, Seal B, Hanna N, Mullins CD. Sequential therapies and the cost-effectiveness of treating metastatic colon cancer patients. J Manag Care Spec Pharm. 2016;22(6):628-39. Available at: http://www.jmcp.org/doi/10.18553/jmcp.2016.22.6.628.

20. Du XL, Parikh RC, Lairson DR, Giordano SH, Cen P. Comparative effectiveness of platinum-based chemotherapy versus taxane and other regimens for ovarian cancer. Med Oncol. 2013;30(1):440.

21. Lairson DR, Parikh RC, Cormier JN, Chan W, Du XL. Cost-utility analysis of chemotherapy regimens in elderly patients with stage III colon cancer. Pharmacoeconomics. 2014:32(10):1005-13.

22. Thrall MM, Gray HJ, Symons RG, Weiss NS, Flum DR, Goff BA. Trends in treatment of advanced epithelial ovarian cancer in the Medicare population. Gynecol Oncol. 2011;122(1):100-06.

23. Thrall MM, Gray HJ, Symons RG, Weiss NS, Flum DR, Goff BA. Neoadjuvant chemotherapy in the Medicare cohort with advanced ovarian cancer. Gynecol Oncol. 2011;123(3):461-66.

24. Gruschkus SK, Lairson D, Dunn JK, Risser J, Du XL. Comparative effectiveness of white blood cell growth factors on neutropenia, infection, and survival in older people with non-Hodgkin's lymphoma treated with chemotherapy. J Am Geriatr Soc. 2010;58(10):1885-95.

25. Du XL, Osborne C, Goodwin JS. Population-based assessment of hospitalizations for toxicity from chemotherapy in older women with breast cancer. J Clin Oncol. 2002;20(24):4636-42.

26. National Cancer Institute. Colon cancer treatment (PDQ)-health professional version. Updated August 12, 2016. Available at: http://cancer.gov/ cancertopics/pdq/treatment/colon/HealthProfessional. Accessed November 20, 2016.

27. Hess GP, Wang PF, Quach D, Barber B, Zhao Z. Systemic therapy for metastatic colorectal cancer: patterns of chemotherapy and biologic therapy use in U.S. medical oncology practice. J Oncol Pract. 2010;6(6):301-07.

28. Seal BS, Sullivan SD, Ramsey SD, et al. Systemic therapy for colorectal cancer: patterns of chemotherapy and biologic therapy use in nationally representative U.S. claims database. BioDrugs. 2014;28(2):229-36.

29. Abrams TA, Meyer G, Schrag D, Meyerhardt JA, Moloney J, Fuchs CS. Chemotherapy usage patterns in a U.S.-wide cohort of patients with metastatic colorectal cancer. J Natl Cancer Inst. 2014;106(2):djt371.

30. Parikh RC, Du XL, Morgan RO, Lairson DR. Patterns of treatment sequences in chemotherapy and targeted biologics for metastatic colorectal cancer: findings from a large community-based cohort of elderly patients. Drugs Real World Outcomes. 2016;3(1):69-82.

31. TreeAge Software. TreeAge Pro 2015 user's manual: time-to-event simulation. Available at: http://installers.treeagesoftware.com/treeagepro/15.1.0/20150102/TP-Manual-TP2015.pdf. Accessed November 20, 2016.

32. Chrosny W, Stevenson M, Munzer A. Comparison of Markov and discrete event simulation modeling techniques with application to cost effectiveness analyses. Value Health. 2013;16(7):A587 [Abstract PRM70]. Available at: http://www.valueinhealthjournal.com/article/S1098-3015(13)03528-6/ pdf. Accessed November 20, 2016.

33. Drummond MF, Sculpher MJ, Torrance GW, O'Brien BJ, Stoddart GL. Methods for the Economic Evaluation of Health Care Programmes. 3rd ed. New York: Oxford University Press; 2005.

34. Briggs AH, Claxton K, Sculpher MJ. Decision Modelling for Health Economic Evaluation. New York: Oxford University Press; 2006.

35. Gray AM, Clarke PM, Wolstenholme JL, Wordsworth S. Applied Methods of Cost-Effectiveness Analysis in Healthcare. New York: Oxford University Press; 2010 36. Wu B, Dong B, Xu Y, et al. Economic evaluation of first-line treatments for metastatic renal cell carcinoma: a cost-effectiveness analysis in a health resource-limited setting. PloS One. 2012;7(3):e32530. 
37. Zhu H, Xia X, Yu C, Adnan A, Liu S, Du Y. Application of Weibull model for survival of patients with gastric cancer. BMC Gastroenterol. 2011;11:1.

38. Murphy SL, Xu J, Kochanek KD. Deaths: final data for 2010. Natl Vital Stat Rep. 2013;61(4):1-117.

39. Siegel R, DeSantis C, Jemal A. Colorectal cancer statistics, 2014. CA Cancer J Clin. 2014;64(2):104-17.

40. Brown ML, Riley GF, Schussler N, Etzioni R. Estimating health care costs related to cancer treatment from SEER-Medicare data. Med Care. 2002;40(8 Suppl):104-IV-117.

41. Bureau of Labor Statistics. Consumer Price Index. Medical care. 2014. Available at: http://data.bls.gov/cgi-bin/surveymost?cu. Accessed November 20, 2016

42. Ramsey SD, Andersen MR, Etzioni R, et al. Quality of life in survivors of colorectal carcinoma. Cancer. 2000;88(6):1294-303.

43. Stein D, Joulain F, Naoshy S, et al. Assessing health-state utility values in patients with metastatic colorectal cancer: a utility study in the United Kingdom and the Netherlands. Int J Colorectal Dis. 2014;29(10):1203-10.

44. Starling N, Tilden D, White J, Cunningham D. Cost-effectiveness analysis of cetuximab/irinotecan vs active/best supportive care for the treatment of metastatic colorectal cancer patients who have failed previous chemotherapy treatment. Br J Cancer. 2007;96(2):206-12.

45. Bennett L, Zhao Z, Barber B, et al. Health-related quality of life in patients with metastatic colorectal cancer treated with panitumumab in first-or second-line treatment. Br J Cancer. 2011;105(10):1495-502.

46. Health Quality Ontario. KRAS testing for anti-EGFR therapy in advanced colorectal cancer: an evidence-based and economic analysis. Ontario Health Technol Assess Ser. 2010;10(25):1-49.

47. Malin JL. Wrestling with the high price of cancer care: should we control costs by individuals' ability to pay or society's willingness to pay? J Clin Oncol. 2010 10;28(20):3212-14.

48. Garau M, Shah KK, Mason AR, Wang Q, Towse A, Drummond MF Using QALYs in cancer. Pharmacoeconomics. 2011;29(8):673-85.

49. Briggs AH, Goeree R, Blackhouse G, O'Brien BJ. Probabilistic analysis of cost-effectiveness models: choosing between treatment strategies for gastroesophageal reflux disease. Med Decis Making. 2002;22(4):290-308.

50. Lee CP, Chertow GM, Zenios SA. An empiric estimate of the value of life: updating the renal dialysis cost-effectiveness standard. Value Health. 2009;12(1):80-87.

51. Mehta DA, Hay JW. Cost-effectiveness of adding bevacizumab to first line therapy for patients with advanced ovarian cancer. Gynecol Oncol. 2014;132(3):677-83.

52. Barnett JC, Alvarez Secord A, Cohn DE, Leath CA, Myers ER, Havrilesky LJ Cost effectiveness of alternative strategies for incorporating bevacizumab into the primary treatment of ovarian cancer. Cancer. 2013;119(20):3653-61.

53. Goldstein DA, Chen Q, Ayer T, et al. First- and second-line bevacizumab in addition to chemotherapy for metastatic colorectal cancer: a United States-based cost-effectiveness analysis. J Clin Oncol. 2015;33(10):1112-18.
54. Mullard A. Can next-generation antibodies offset biosimilar competition? Nat Rev Drug Discov. 2012;11(6):426-28.

55. Smith BD, Smith GL, Hurria A, Hortobagyi GN, Buchholz TA. Future of cancer incidence in the United States: burdens upon an aging, changing nation. J Clin Oncol. 2009;27(17):2758-65.

56. Mariotto AB, Yabroff KR, Shao Y, Feuer EJ, Brown ML. Projections of the cost of cancer care in the United States: 2010-2020. J Natl Cancer Inst. 2011;103(2):117-28.

57. Sanoff HK, Goldberg RM. How we treat metastatic colon cancer in older adults. J Geriatr Oncol. 2013;4(4):295-301.

58. Vargas GM, Sheffield KM, Parmar AD, et al. Trends in treatment and survival in older patients presenting with stage IV colorectal cancer. J Gastrointest Surg. 2014;18(2):369-77.

59. Mehta HB, Vargas GM, Tamirisa NP, Adhikari D, Brown KM, Riall TS. Comparative effectiveness of chemotherapy versus resection of the primary tumor as the initial treatment modality in older patients with stage IV colorectal cancer. Pharmacoepidemiol Drug Saf. 2015;24(Suppl S1):224-25 [Abstract 398].

60. Istituto Scientifico Romagnolo per lo Studio e la cura dei Tumori. Sequential treatment strategy for metastaticcolorectal cancer (ITACa). 2014 ClinicalTrials.gov Identifier NCT01878422. Available at: http://clinicaltrials, gov/show/NCT01878422. Accessed November 20, 2016.

61. Passardi A, Nanni O, Tassinari D, et al. Effectiveness of bevacizumab added to standard chemotherapy in metastatic colorectal cancer: final results for first-line treatment from the ITACa randomized clinical trial. Ann Oncol. 2015;26(6):1201-07.

62. Chibaudel B, Bonnetain F, Tournigand C, et al. STRATEGIC-1: a multiple-lines, randomized, open-label GERCOR phase III study in patients with unresectable wild-type RAS metastatic colorectal cancer. BMC Cancer. $2015 ; 15: 496$.

63. Zippin C, Lum D, Hankey BF. Completeness of hospital cancer case reporting from the SEER Program of the National Cancer Institute. Cancer. 2006;76(11):2343-50

64. Engels EA, Pfeiffer RM, Ricker W, Wheeler W, Parsons R, Warren JL. Use of Surveillance, Epidemiology, And End Results-Medicare data to conduct case-control studies of cancer among the U.S. elderly. Am J Epidemiol. 2011;174(7):860-70.

65. Warren JL, Harlan LC, Fahey A, et al. Utility of the SEER-Medicare data to identify chemotherapy use. Med Care. 2002;40(8 Suppl):IV-55-61.

66. Hamilton L. Using SAS to identify cancer treatment patterns in administrative claims data. Paper presented at: NESUG 2011 Conference; Portland, ME; October 2011. Available at: http://www.lexjansen.com/nesug/nesugll/ ph/ph07.pdf. Accessed November 20, 2016.

67. Austin PC. An introduction to propensity score methods for reducing the effects of confounding in observational studies. Multivariate Behav Res. 2011;46(3):399-424

68. Rosenbaum PR, Rubin DB. The central role of the propensity score in observational studies for causal effects. Biometrika. 1983;70(1):41-55. 


\section{APPENDIX A Descriptions of Data Source, Treatment Sequences, and Inverse Probability} Treatment Weighting

Data Source

The Surveillance, Epidemiology, and End Results (SEER) program is managed by the National Cancer Institute and collects information on patient demographics and tumor characteristics for cancer patients from participating registries in the United States. After the increase of participating registries in 2000 , SEER represents nearly $28 \%$ of the U.S. population, and $98 \%$ of cases diagnosed in the participating regions are recorded in SEER. Through Medicare linkage, the data provide health care utilization and cost information for inpatient, outpatient, professional (provider), skilled nursing facility, hospice, and devices and medical equipment for elderly patients aged 65 years and older. The data have been used for cancer epidemiology and chemotherapy utilization studies, validity for chemotherapy receipt, and case reporting. Completeness of the database has been shown in previous studies. ${ }^{63-65}$

\section{Treatment Line and Sequences}

Healthcare Common Procedure Coding System codes were used to identify chemotherapy or targeted biologic, that is, 5-florouracil (J9190); irinotecan (J9206); leucovorin (J0640, J0641); oxaliplatin (J9263, C9205); bevacizumab (J9035, C9214, S0116); cetuximab (J9055, C9215); and panitumumab (J9303, C9235). Sequence identification was conducted in 2 steps. First, treatment line of chemotherapy and targeted biologics were identified using methodology applied in previous studies. ${ }^{27-30}$ The start of a treatment line was determined based on the date of the first claim for the drug and was required to be readministered within 35 days ( $28+7$ additional days). A combination regimen was defined when an additional drug was administered within 28 days of the first drug claim and was readministered within 35 days ( $28+7$ additional days). The end of a treatment line was defined as follows: (a) a line continues until the end of the study; (b) no drug was administered within 90 days, or (c) a previous line of treatment was interrupted by a new line of treatment. 66 This step was repeated 3 times to identify the first 3 lines of treatment administered longitudinally to metastatic colorectal cancer patients. Second, for patients who received multiple lines of treatment (i.e., more than 2 lines of treatment) and the gap between treatments was less than a year, the treatment lines were combined to define treatment sequences.

\section{Inverse Probability Treatment Weighting}

The propensity score approach has been widely accepted in epidemiology literature to adjust for systematic and observable differences that may exist among exposed and unexposed groups. ${ }^{67,68} \mathrm{~A}$ propensity score is the predicted probability of receiving 1 treatment versus the other, while adjusting for observed variables in the regression (a logistic regression for 2 treatment arms and a multinomial logistic regression for more than 2 arms). ${ }^{67,68}$ Once a propensity score is obtained for each individual, it could be used in multiple ways to balance treatment groups based on observable characteristics. Commonly used strategies are classifying patients into stratums based on propensity scores, conducting a l-to-l matching, using the propensity score as adjustment in regression or using inverse probability weighing. 67,68 Propensity score matching is currently limited to 3 groups, and since 4 treatment sequences were compared in the study, the inverse probability treatment weighting technique was used. The input parameters obtained were adjusted for inverse probability treatment weights computed using observed characteristics. The characteristics included were age, race, gender, marital status, tumor grade, comorbidity score, metastasis type, cancer site, socioeconomic status, geographic region, urban/rural, and year of diagnosis.

a Footnotes in this appendix refer to the references cited at the end of this article. 
Cost-Effectiveness of Treatment Sequences of Chemotherapies and Targeted Biologics for Elderly Metastatic Colorectal Cancer Patients

\section{APPENDIX B Patient Exclusion Flowchart}

Patients with American Joint Cancer Committee

stage IV mCRC

$\mathrm{N}=17,207$

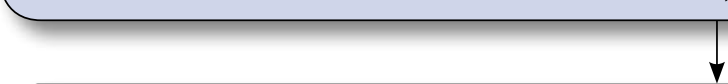

Patients diagnosed with $\mathrm{mCRC}$ in reporting services

other than autopsy and death certificate

$\mathrm{n}=17,182$

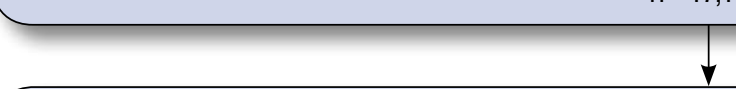

Patients eligible for full enrollment in Medicare Part A and B and not enrolled in

HMO from time of diagnosis to time of death or study end, whichever came first $n=11,838$

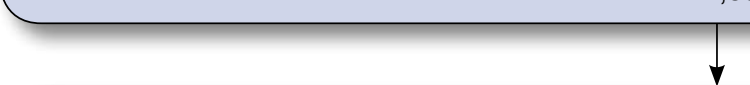

Patients who were alive after 30 days of diagnosis $n=9,819$

Patients who received treatment with chemotherapy or targeted therapy $n=4,418$

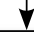

Patients who received at least 2 lines of treatment $n=2,534$

$\mathrm{HMO}=$ health maintenance organization; $m C R C=$ metastatic colorectal cancer 
Cost-Effectiveness of Treatment Sequences of Chemotherapies and

Targeted Biologics for Elderly Metastatic Colorectal Cancer Patients

\section{APPENDIX C Commonly Received Treatment Sequences and Duration by Line of Therapy for Elderly} Metastatic Colorectal Cancer Patients

\begin{tabular}{|c|c|c|c|c|c|c|c|c|c|}
\hline \multirow{2}{*}{$\begin{array}{l}\text { First-Line } \\
\text { Treatment }\end{array}$} & \multirow{2}{*}{$\begin{array}{c}\text { Second-Line } \\
\text { Treatment }\end{array}$} & \multirow{2}{*}{$\begin{array}{l}\text { Third-Line } \\
\text { Treatment }\end{array}$} & \multirow{2}{*}{\begin{tabular}{|c|}
$\mathrm{N}(\%)$ \\
Total, $\mathrm{N}=821$
\end{tabular}} & \multicolumn{2}{|c|}{ First Line (Days) } & \multicolumn{2}{|c|}{ Second Line (Days) } & \multicolumn{2}{|c|}{ Third Line (Days) } \\
\hline & & & & Mean [SD] & Median & Mean [SD] & Median & Mean [SD] & Median \\
\hline OX/IR & $\mathrm{OX} / \mathrm{IR}+\mathrm{BV}$ & Targeted biologic & $275 \quad(33.5)$ & $114.2 \quad[93.6]$ & 86 & $195.2[152.8]$ & 160 & $188.6[160.4]$ & 146 \\
\hline OX/IR+BV & $\mathrm{OX} / \mathrm{IR}+\mathrm{BV}$ & Targeted biologic & $199 \quad(24.2)$ & 204.7 [119.2] & 195 & $187.4[153.7]$ & 143 & $165.0 \quad[121.8$ & 132 \\
\hline OX/IR & $\mathrm{OX} / \mathrm{IR}+\mathrm{BV}$ & NA & $178 \quad(21.7)$ & $110.2 \quad[79.4]$ & 83 & 169.7 [119.7] & 136 & NA & NA \\
\hline OX/IR+BV & OX/IR+BV & NA & $169 \quad(20.6)$ & 197.8 [141.7] & 168 & $184.4[163.0]$ & 145 & NA & $\mathrm{NA}$ \\
\hline
\end{tabular}

\section{APPENDIX D Time-to-Event Input Parameters from Parametric Survival Analyses}

\begin{tabular}{|c|c|c|c|c|}
\hline \multirow[b]{2}{*}{ Treatment Sequence/Line of Treatment } & \multicolumn{2}{|c|}{ Weibull Distribution } & \multicolumn{2}{|c|}{ Log-Normal Distribution } \\
\hline & Weibull Scale & Weibull Shape & Mean & Standard Deviation \\
\hline \multicolumn{5}{|l|}{ OI-OIB } \\
\hline Diagnosis to first line & 77.1407 & 1.2457 & 3.9704 & 0.7617 \\
\hline First line to second line & 149.0602 & 1.3378 & 4.6162 & 0.7551 \\
\hline Second line to death & 528.8745 & 0.9286 & 5.7431 & 1.1147 \\
\hline \multicolumn{5}{|l|}{ OIB-OIB } \\
\hline Diagnosis to first line & 77.1407 & 1.2457 & 3.9704 & 0.7617 \\
\hline First line to second line & 300.6160 & 1.5927 & 5.3673 & 0.7049 \\
\hline Second line to death & 550.0627 & 1.0798 & 5.8469 & 0.9694 \\
\hline \multicolumn{5}{|l|}{ OI-OIB-TB } \\
\hline Diagnosis to first line & 77.1407 & 1.2457 & 3.9704 & 0.7617 \\
\hline First line to second line & 144.5266 & 1.2475 & 4.5708 & 0.7763 \\
\hline Second line to second line end & 208.5981 & 1.5169 & 5.0208 & 0.6319 \\
\hline Third line to death & 520.9412 & 1.3748 & 5.8775 & 0.8338 \\
\hline \multicolumn{5}{|l|}{ OIB-OIB-TB } \\
\hline Diagnosis to first line & 77.1407 & 1.2457 & 3.9704 & 0.7617 \\
\hline First line to second line & 302.1773 & 1.8083 & 5.3899 & 0.6857 \\
\hline Second line to second line end & 205.5539 & 1.4155 & 4.9958 & 0.6366 \\
\hline Third line to death & 457.7406 & 1.1259 & 5.6808 & 1.0157 \\
\hline
\end{tabular}


Cost-Effectiveness of Treatment Sequences of Chemotherapies and

Targeted Biologics for Elderly Metastatic Colorectal Cancer Patients

\section{APPENDIX E Input Parameters for Cost and Health State Utilities}

\begin{tabular}{|c|c|c|c|}
\hline Treatment Sequence/Line of Treatment & Mean & Standard Deviation & Distribution for PSA \\
\hline \multicolumn{4}{|l|}{ Cost Per Month (2014 U.S. Dollars) } \\
\hline \multicolumn{4}{|l|}{ OI-OIB } \\
\hline Diagnosis to first line & 14,585 & 8,306 & Gamma \\
\hline First line to second line & 11,873 & 6,182 & Gamma \\
\hline Second line to death & 13,815 & 10,142 & Gamma \\
\hline \multicolumn{4}{|l|}{ OIB-OIB } \\
\hline Diagnosis to first line & 13,215 & 7,502 & Gamma \\
\hline First line to second line & 13,632 & 8,060 & Gamma \\
\hline Second line to death & 12,004 & 8,458 & Gamma \\
\hline \multicolumn{4}{|l|}{ OI-OIB-TB } \\
\hline Diagnosis to first line & 14,097 & 8,406 & Gamma \\
\hline First line to second line & 11,542 & 5,736 & Gamma \\
\hline Second line to second line end & 15,438 & 8,289 & Gamma \\
\hline Third line to death & 12,922 & 7,955 & Gamma \\
\hline \multicolumn{4}{|l|}{ OIB-OIB-TB } \\
\hline Diagnosis to first line & 14,027 & 8,620 & Gamma \\
\hline First line to second line & 13,530 & 6,313 & Gamma \\
\hline Second line to second line end & 13,805 & 7,568 & Gamma \\
\hline Third line to death & 13,742 & 9,646 & Gamma \\
\hline \multicolumn{4}{|l|}{ Health state utilities } \\
\hline Diagnosis & 0.840 & 0.120 & Beta \\
\hline First line/second line & 0.741 & 0.230 & Beta \\
\hline Third line & 0.731 & 0.292 & Beta \\
\hline
\end{tabular}

OI-OIB = first-line oxaliplatin/irinotecan followed by second-line oxaliplatin/irinotecan + bevacizumab; OIB-OIB =first-line oxaliplatin/irinotecan + bevacizumab followed by second-line oxaliplatin/irinotecan + bevacizumab; OI-OIB-TB = OI-OIB followed by a third-line targeted biologic; OIB-OIB-TB=OIB-OIB followed by a third-line targeted biologic; PSA = probabilistic sensitivity analysis. 